\title{
Function of the anal sphincters in patients with intussusception of the rectum
}

\author{
B. FRENCKNER AND T. IHRE
}

From the Department of Clinical Physiology and the Department of Surgery, Serafimer Hospital, Stockholm, Sweden

SUMMARY Patients with intussusception of the rectum-six with anal incontinence and nine continent-were examined with respect to the function of the anal sphincters. Anal pressure was recorded continuously during rest, during maximal voluntary squeezing of the anal muscles, and during gradual expansion of the rectum by means of a balloon inserted into the rectal ampulla. The maximal anal pressure at rest, which is mainly due to activity of the internal anal sphincter, was lower $(\mathrm{P}<0.001)$ in the incontinent patients $(31 \mathrm{mmHg} \pm 5.6)$ than the continent $(67 \mathrm{mmHg} \pm 4.3)$ and the former had significantly smaller relaxations of the internal sphincter upon rectal distension $(P<0.05)$. The increase in anal pressure during voluntary squeezing, a function of the external sphincter, did not differ significantly compared with healthy subjects in either incontinent or continent patients. On the basis of the above findings, it is concluded that the function of the internal sphincter is impaired in the incontinent patients.

Intussusception of the rectum (internal procidentia) is an intussusception of the rectal wall which begins as a circular fold $6-8 \mathrm{~cm}$ up in the rectum and develops into a condition in which the entire rectal wall folds in toward the rectal lumen. In connection with straining, this infolding gradually increases, so that it finally fills the entire ampulla and may act as a dilator of the anal canal. In patients with rectal prolapse, this infolding process continues out through the anal canal. The condition was first described by Tuttle (1902) and, since then, other authors (Bacon, 1949; Asman, 1957; Brodén and Snellman, 1968; Ihre, 1972; Ihre and Seligson, 1975) have contributed to our understanding of its pathogenesis and symptoms. The most common complaint is difficulty in bowel emptying. Another common symptom is incontinence of gas and/or faeces.

The anal canal is surrounded by two layers of muscles, the smooth internal sphincter and the striated outer layer, the latter being composed of the puborectalis muscle and the external anal sphincter. When the rectum is moderately distended in healthy subjects, there is a brief contraction of the striated muscles (Gaston, 1948; Goligher and Hughes, 1951) and a transient relaxation of the internal sphincter (Gowers, 1877; Denny-Brown and Robertson, 1935). Upon further distension, the tone of the internal

Received for publication 7 November 1975 sphincter does not return to its original level (Gaston, 1948; Kerremans, 1969; Ihre, 1974), a phenomenon which has been termed constant relaxation. In patients with intussusception of the rectum, this constant relaxation seems to occur at smaller rectal volumes among those who are incontinent than among continent (Ihre, 1974), thus suggesting that the function of the internal sphincter may be impaired in the former.

The present study was undertaken in order further to elucidate the possible difference in internal anal sphincter function between continent and incontinent patients with intussusception of the rectum. Manometric recordings of anal pressure were obtained for quantitative assessments of the activity of the internal anal sphincter, which is known to contribute the main part of anal pressure at rest (Duthie and Watts, 1965; Frenckner and v. Euler, 1975).

\section{Methods}

\section{SUBJECTS}

Fifteen patients, all female, with intussusception of the rectum were examined. The diagnosis was established cineradiographically, using the technique described by Brodén and Snellman (1968). None of the patients had been operated upon for the intussusception and the only other anorectal disorders 
were minor internal haemorrhoids in two patients (nos. 6 and 10). Six patients were incontinent and nine continent with respect to gas and/or faeces, incontinence being defined as an inability to control the passage of gas and/or faeces through the anus. No distinction was made between patients who had rare as opposed to daily occurrences of these episodes.

The main complaint of the six incontinent patients, mean age 69 years (56-81 years), was anal incontinence. Two of them (nos. 1 and 2) also complained of difficulties over bowel emptying. The nine continent patients with intussusception, mean age 64 years (47-79 years), were randomly selected from patients with this disorder who were known at the Surgical Department of the Serafimer Hospital and belonged to the same age group as the incontinent patients. The main complaint of all was difficulties in bowel emptying. In addition, one (no. 7) complained of pain in the lower abdomen.

\section{PROCEDURE}

The subjects were placed in the left supine position with the hips flexed $90^{\circ}$. A digital examination of the anal canal and rectum was performed before the investigator, using a proctoscope, inserted a latex balloon in the rectum $6-8 \mathrm{~cm}$ above the anal verge. The balloon, which measured about $3 \times 1.5 \mathrm{~cm}$ when empty, was connected to a polyethylene tube about $75 \mathrm{~cm}$ long with an internal diameter of 2.0 $\mathrm{mm}$ and an external of $2.2 \mathrm{~mm}$. When the proctoscope had been removed, the balloon was inflated with $50 \mathrm{ml}$ of air (which was immediately evacuated) to ensure that it lay unfolded. The polyethylene tube was connected via a threeway stopcock to a $50 \mathrm{ml}$ glass syringe and to an electric pressure transducer (EMT 34, Siemens-Elema), which led in turn after amplification (EMT 31, Siemens-Elema) to an ink-jet recorder (Mingograph 42B, Siemens-Elema). After approximately five minutes rest, an instrument with a water-filled balloon (Fig. 1) was introduced into the anal canal in order to record the anal pressure. This instrument consists of a metal cylinder fitted with a latex balloon and has a hole down its centre, through which the polyethylene tube to the rectal balloon passed. The water-filled anal balloon was also connected to the Mingograph recorder via an

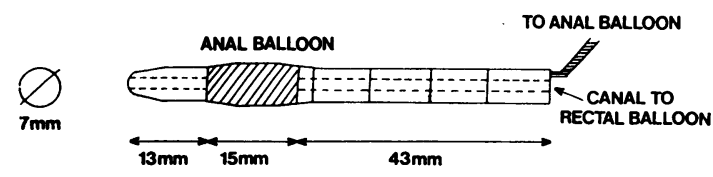

Fig. 1 Diagrammatic drawing of the device for measuring pressure in the anal canal. It consists of a metal cylinder fitted with a latex balloon. electrical pressure transducer (EMT 34) and an amplifier (EMT 31). Anal pressure was recorded at distances of $1,2,3$, and $4 \mathrm{~cm}$ from the anal verge and the balloon was then placed at the distance with the highest pressure; this will be referred to below as maximal anal pressure. A continuous recording lasting a few minutes was made and the subject was then told to squeeze briefly the voluntary anal muscles maximally three times while the increase in maximal anal pressure was recorded. A few minutes later the rectal balloon was inflated with air during continuous recording of anal pressure. The inflation started with $20 \mathrm{ml}$, then $30 \mathrm{ml}$, and then portions of $50 \mathrm{ml}$ with an interval of $30 \mathrm{~s}$. It took approximately $0 \cdot 5-1.0 \mathrm{~s}$ to fill each portion. Filling was stopped either when the balloon was involuntarily defaecated, or when the subject was unable to tolerate any further expansion of the rectum, or when the balloon had been filled to capacity $(500 \mathrm{ml})$, whereupon it was evacuated.

\section{STATISTICS}

Standard statistical methods were employed, using the $t$ test when applicable. In one instance the $\chi^{2}$ test of independence was used. Data in the text, table, and figures are given as mean $\pm \mathrm{SE}$ (standard error of the mean).

\section{Results}

During rest, the maximal anal pressure (Table) remained on a stable level in every patient. In none of the incontinent subjects was it above $50 \mathrm{mmHg}$ and only one of the continent patients (no. 14) showed a pressure below this. The mean of the

\begin{tabular}{|c|c|c|c|c|c|}
\hline \multicolumn{3}{|c|}{ Incontinent subjects } & \multicolumn{3}{|c|}{ Continent subjects } \\
\hline $\begin{array}{l}\text { Pat. } \\
\text { no. }\end{array}$ & $\begin{array}{l}\text { Maximal } \\
\text { anal } \\
\text { pressure } \\
(\mathrm{mmHg})\end{array}$ & $\begin{array}{l}\text { Increase by } \\
\text { voluntary } \\
\text { squeeze } \\
(\mathrm{mmHg})\end{array}$ & $\begin{array}{l}\text { Pat. } \\
\text { no. }\end{array}$ & $\begin{array}{l}\text { Maximal } \\
\text { anal } \\
\text { pressure } \\
(\mathrm{mmHg})\end{array}$ & $\begin{array}{l}\text { Increase by } \\
\text { voluntary } \\
\text { squeeze } \\
(\mathrm{mmHg})\end{array}$ \\
\hline $\begin{array}{l}1 \\
2 \\
3 \\
4 \\
5 \\
6\end{array}$ & $\begin{array}{l}40 \\
50 \\
32 \\
20 \\
30 \\
12\end{array}$ & $\begin{array}{l}42 \\
16 \\
84 \\
40 \\
74 \\
14\end{array}$ & $\begin{array}{r}7 \\
8 \\
9 \\
10 \\
11 \\
12 \\
13 \\
14 \\
15\end{array}$ & $\begin{array}{l}80 \\
60 \\
85 \\
80 \\
68 \\
64 \\
52 \\
47 \\
64\end{array}$ & $\begin{array}{r}- \\
30 \\
31 \\
120 \\
36 \\
42 \\
40 \\
91 \\
56\end{array}$ \\
\hline $\mathrm{m} \pm \mathrm{SE}$ & $31 \pm 5 \cdot 6$ & $45 \pm 11 \cdot 8$ & $\mathbf{m} \pm$ & E $67 \pm 4 \cdot 3$ & $56 \pm 11 \cdot 6$ \\
\hline \multicolumn{3}{|c|}{ Healthy controls } & \multicolumn{2}{|c|}{$m \pm S E 65 \pm 3.7^{*}$} & $63 \pm 14 \cdot 7 \dagger$ \\
\hline
\end{tabular}

Table Maximal anal pressure and increase of anal pressure by voluntary squeeze in incontinent and continent patients

*According to combined results of Frenckner and v. Euler (1975) and Frenckner (1975) $n=14$.

†According to Frenckner and v. Euler $(1975)(n=9)$ 
pressures recorded in incontinent subjects, $31 \mathrm{mmHg}$ $\pm 5 \cdot 6$, was lower than in the continent subjects, $67 \mathrm{mmHg} \pm 4 \cdot 3$, the difference being highly significant $(P<0.001)$. Combining the results of earlier studies (Frenckner, 1975; Frenckner and v. Euler, 1975), maximal anal pressure recorded with the same method in healthy subjects averaged $65 \mathrm{mmHg} \pm$ $3.7(n=14)$. Thus the continent subjects with intussusception of the rectum do not seem to differ from healthy subjects in this respect.

Each patient was told to squeeze the voluntary anal muscles maximally three times and the increase in anal pressure was recorded each time (Figs 2 and 3). The mean for each subject was obtained (Table) and the incontinent and continent patients were compared. The average increase in anal pressure among the incontinent was $45 \mathrm{mmHg} \pm 12$ and among the continent $56 \mathrm{mmHg} \pm 12$, the difference not being statistically significant. In earlier studies (Frenckner and v. Euler, 1975), the corresponding increase in healthy subjects was $63 \mathrm{mmHg} \pm 15$ ( $\mathrm{n}=9$ ), which, compared with the incontinent subjects, is again not statistically significant.

When the rectum was expanded by inflations of

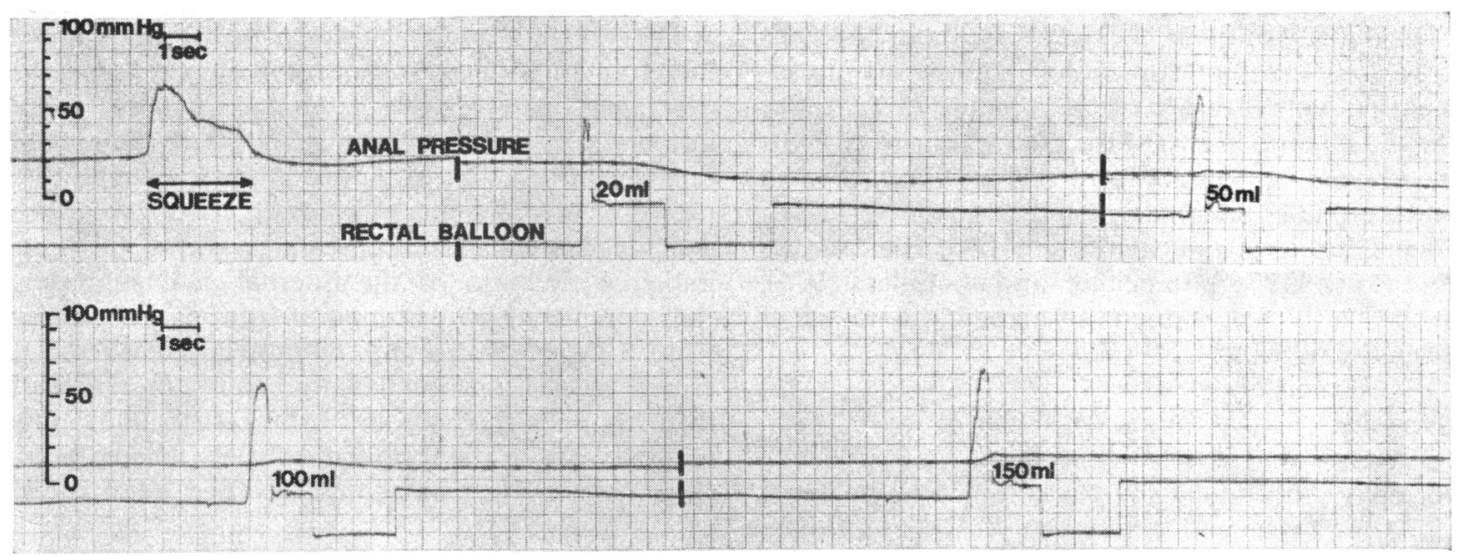

Fig. 2 Recording of anal pressure during voluntary squeezing and during stepwise filling of the rectum in an incontinent subject. There is a low maximal anal pressure at rest and the relaxations upon rectal distension are very small. The lower curve representing rectal balloon pressure indicates when the insufflations of air were performed. After each insufflation there is a short recording of zero pressure.

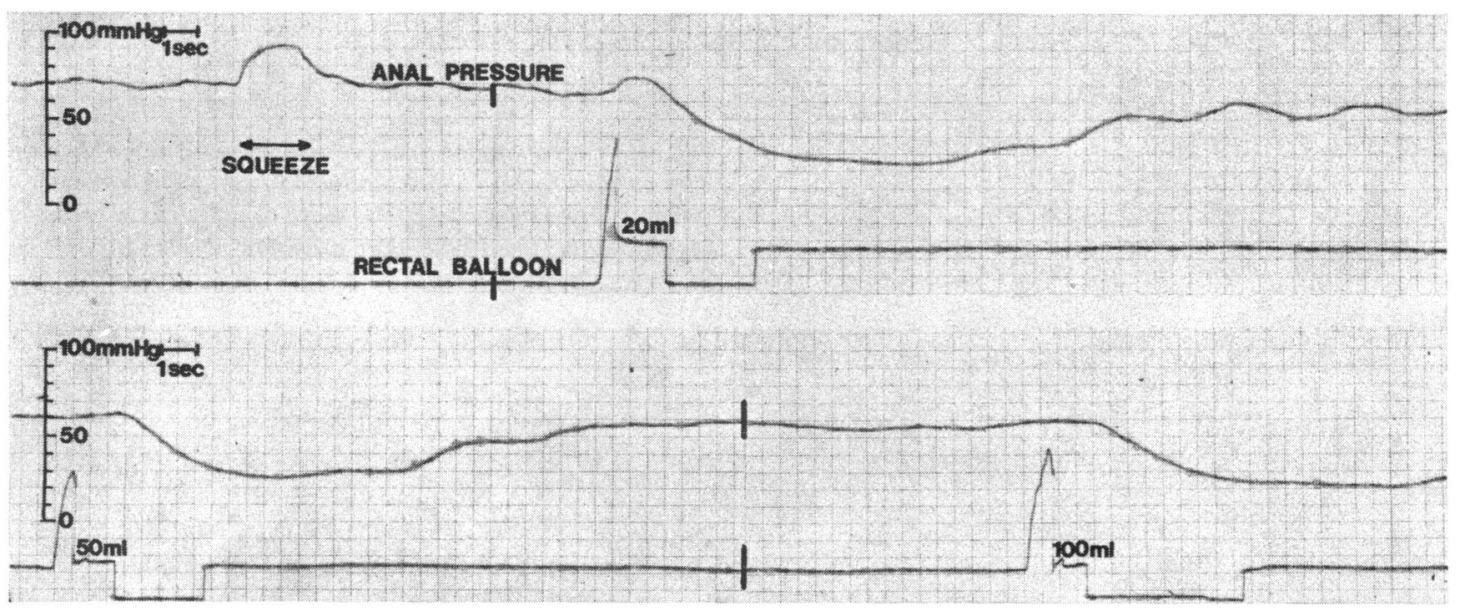

Fig. 3 Recording of anal pressure during voluntary squeezing and during stepwise filling of the rectum in a continent subject. The lower curve representing rectal balloon pressure indicates when the insufflations of air were performed. After each insufflation there is a short recording of zero pressure. 
air in the rectal balloon, anal pressure relaxed in all patients (Figs 2 and 3); in some cases, these relaxations were preceded by a brief increase in pressure. On the average, the relaxations were deeper and lasted longer the more the rectum was distended. They were also deeper among patients with a high resting pressure-that is, in general, the continent subjects. This difference between incontinent and continent patients was significant $(P<0.05)$ for all rectal volumes from $20 \mathrm{ml}$ to $200 \mathrm{ml}$. Thus the remaining anal pressure during relaxation (Fig. 4) fell more rapidly with increasing rectal volume among the continent subjects and averaged $28 \mathrm{mmHg}$ at a moderate rectal distension $(100-200 \mathrm{ml})$, compared with $16 \mathrm{mmHg}$ among the incontinent subjects.

During inflation of the rectal balloon, this was defaecated involuntarily in four of the six incontinent patients (average rectal volume $325 \mathrm{ml}$, range $200-450 \mathrm{ml}$ ) and in two of the nine continent patients (rectal volumes of 300 and $350 \mathrm{ml}$ respectively). However, this difference, tested with the $\chi^{2}$ test of independence, is not significant. In earlier studies (Frenckner, 1975; Frenckner and v. Euler, 1975), involuntary defaecation in this manner did not occur in healthy subjects.

\section{Discussion}

Normally, the anal canal is completely collapsed

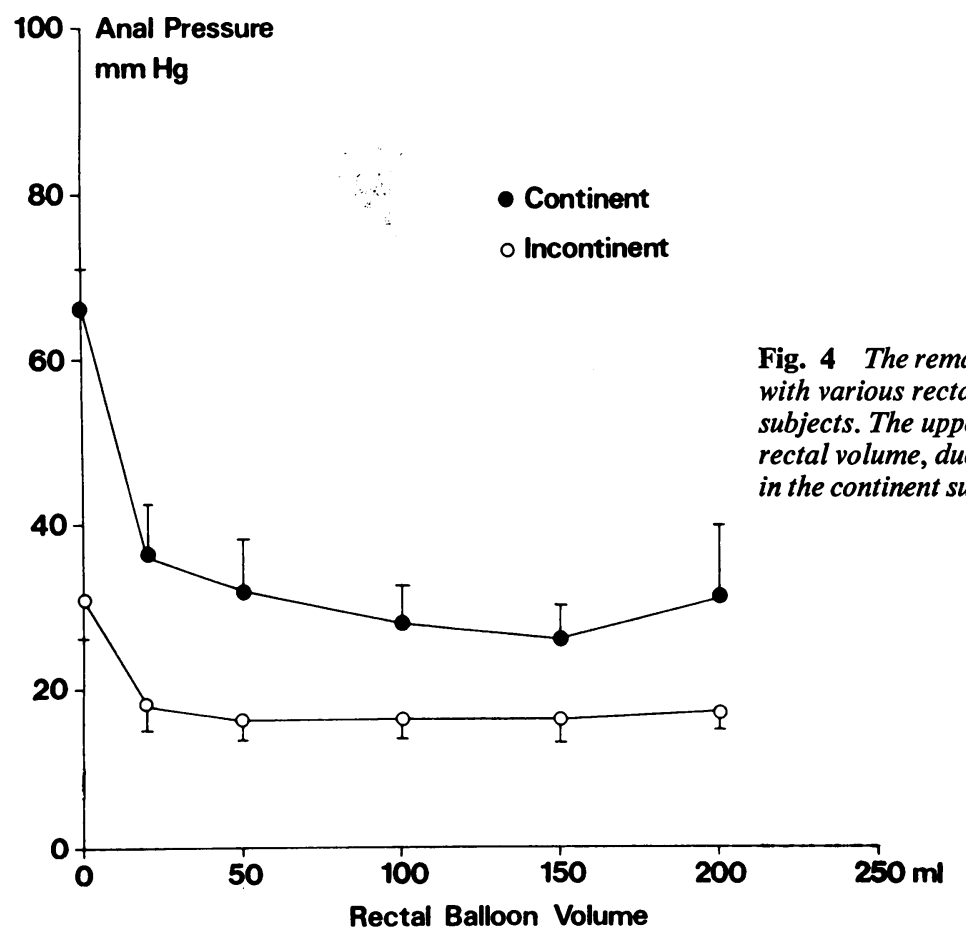

because of the tonic contraction of the anal sphincters. When the anal balloon is introduced, this dilates the anal canal and the anal sphincters generate a force which acts on the surface of the balloon and is transmitted through this to the water inside. Anal pressure is defined as the pressure which is then recorded inside the balloon. Because of its construction and, as it is filled with water, its shape does not change at different pressures. This is important, as a pressure recorded inside an anal balloon depends to a great extent upon the balloon's size and shape (Hill et al., 1960).

According to earlier investigations (Duthie and Watts, 1965; Frenckner and v. Euler, 1975), the maximal anal pressure at rest is governed mainly by activity of the smooth internal sphincter, which can therefore be studied by recording anal pressure. In this investigation, the continent patients with intussusception of the rectum showed a normal anal pressure at rest, but in the incontinent patients the pressure was significantly lower. It is therefore concluded that the incontinent patients have an impaired function of the internal anal sphincter, thus confirming an assumption from earlier studies (Ihre, 1974). Furthermore, $50 \mathrm{mmHg}$ seems to be a critical level of maximal anal pressure, since none of the incontinent patients showed pressures above this and only one of the continent subjects showed pressures below. The relaxations recorded upon rectal

Fig. 4 The remaining anal pressure at maximal relaxation with various rectal volumes in incontinent and continent subjects. The upper curve falls more rapidly with increasing rectal volume, due to the more pronounced relaxation in the continent subjects. 
distension were significantly smaller among the incontinent patients, which is further evidence of an impaired internal sphincter function.

According to cinéradiographic studies (Brodén and Snellman, 1968), the intussusception of the rectum starts with an infolding $6-8 \mathrm{~cm}$ above the anal verge, which, during straining, gradually proceeds downward and, in some patients, dilates the anal canal. It therefore seems reasonable to assume that the damage to the internal sphincter is a result of this dilatation. Furthermore, as every patient (except no. 14) with a defective internal sphincter (as indicated by low maximal anal pressure) was incontinent, it seems that the incontinence may be due to the impaired function of this sphincter.

Voluntary squeezing is accompanied by a contraction of the external sphincter and the puborectalis muscle. The increase in anal pressure is mainly due to the external sphincter (Collins et al., 1969), as its fibres encircle the anal canal. In this investigation both the incontinent and the continent patients showed a somewhat lower increase in anal pressure during voluntary squeezing than that seen in healthy subjects, but the difference was not significant. In other words, no certain difference could be established in the function of the external sphincter. This was also the case in an electromyographic study performed on similar groups of patients (Ihre, 1974).

During the gradual inflations of air in the rectal balloon this was defaecated involuntarily in some cases. This happened more often in incontinent than in continent patients, but the difference was not significant. However, it never occurs in healthy subjects. The cause of such involuntary defaecation of the rectal balloon is not clear, but it has been suggested that it could be due to an impaired function of the striated muscles of the pelvic floor (Frenckner, 1975). The present findings thus support the hypothesis that these muscles may be defective in patients with intussusception of the rectum; this is known to be the case in patients with rectal prolapse (Porter, 1962).

\section{References}

Asman, H. B. (1957). Internal procidentia of the rectum. Southern Medicial Journal, 50, 641-645.

Bacon, H. E. (1949). Anus, Rectum, Sigmoid Colon. 3rd edn, p. 497. Lippincott: Philadelphia.

Brodén, B., and Snellman, B. (1968). Procidentia of the rectum studied with cineradiography: a contribution to the discussion of causative mechanism. Diseases of the Colon and Rectum, 11, 330-347.

Collins, C. D., Brown, B. H., Whittaker, G. E., and Duthie, H. L. (1969). New method of measuring forces in the anal canal. Gut, 10, 160-163.

Denny-Brown, D., and Robertson, E. G. (1935). An investigation of the nervous control of defecation. Brain, 58, 256-310.

Duthie, H. L., and Watts, J. M. (1965). Contribution of the external anal sphincter to the pressure zone in the anal canal. Gut, 6, 64-68.

Frenckner, B. (1975). Function of the anal sphincters in spinal man. Gut, 16, 638-644.

Frenckner, B., and v. Euler, C. (1975). Influence of pudendal block on the function of the anal sphincters. Gut, 16, 482-489.

Gaston, E. A. (1948). The physiology of fecal continence. Surgery, Gynecology, and Obstetrics, 87, 280-290.

Goligher, J. C., and Hughes, E. S. R. (1951). Sensibility of the rectum and colon. Its role in the mechanism of anal continence. Lancet, 1, 543-548.

Gowers, W. R. (1877). The automatic action of the sphincter ani. Proceedings of the Royal Society of London, 26, 77-84.

Hill, J. R., Kelley, M. L., Schlegel, J. F., and Code, C. F. (1960). Pressure profile of the rectum and anus of healthy persons. Diseases of the Colon and Rectum, 3, 203-209.

Ihre, T. (1972). Internal procidentia of the rectum-treatment and results. Scandinavian Journal of Gastroenterology, 7, 643-646.

Ihre, T. (1974). Studies on anal function in continent and incontinent patients. Scandinavian Journal of Gastroenterology, 9, suppl. 25.

Ihre, T., and Seligson, U. (1975). Intussusception of the rectum-internal procidentia: treatment and results in 90 patients. Diseases of the Colon and Rectum, 18, 391-396.

Kerremans, R. (1969). Morphological and Physiological Aspects of Anal Continence and Defaecation. Arscia Uitgaven: Brussels.

Porter, N. H. (1962). A physiological study of the pelvic floor in rectal prolapse. Annals of the Royal College of Surgeons, 31, 379-404.

Tuttle, J. P. (1902). A Treatise on Diseases of the Anus, Rectum and Pelvic Colon, p. 961. Appleton: New York. 